\title{
RESEARCH CORNER
}

Although Public Service Interpreting and Translation (PSIT) can be considered as a relatively 'new' field in Translation Studies, research in this area has increased over the last couple of decades. In the light of the emerging voices claiming that more research should be devoted to PSIT, our first 'Research Corner' offers four examples of PhDs carried out to contribute to make PSIT a consolidated field in Translation Studies.

\section{Author: Luis J. Cayón Sáez}

Title: Court and Police Interpreting in the province of Málaga. A case Study

Year: 2013

Place: University of Málaga (Spain)

Original language: Spanish

The starting point of this $\mathrm{PhD}$ is the research of the foreign population living in the province of Málaga (Spain). The author's main objective is to show the issues and actors involved in court and police interpreting in order to analyze the situation and provide possible solutions to change the current situation and allow the application of the European Directive concerning the assistance of interpreters in court (Criminal Procedures) into the Spanish Legal System.

Author: Almudena Nevado Llopis

Title: Intercultural communication in reproductive health care. Proposals for improvement from public service interpreting and intercultural mediation. A case study of a hospital in Aragón.

Year: 2013

Place: Jaume I University (Castellón, Spain)

Original language: Spanish

The main objective of this academic research consists in studying the linguistic and cultural barriers that healthcare professionals encounter when communicating with foreign languagespeaking patients. In particular, it is focused on intercultural communication in reproductive health care and is based in a case study developed in a maternity hospital in Aragón (Spain). The analysis of the data obtained through document analysis, interviews and focus groups leads to the proposal of some improvement actions that could be implemented in order to facilitate the communication. Among these actions, public service interpreting and intercultural mediation are highlighted as the best way to promote the reciprocal understanding between healthcare professionals and migrant mothers and, ultimately, to guarantee that these women receive appropriate healthcare. 
Author: María A. Aguilar-Solano

Title: Positioning of volunteer interpreters in the field of public service interpreting in Spanish hospitals: A Bourdieusian perspective

Year: 2012

Place: University of Massachusetts Boston (United States)

Original language: English

This thesis is focused on the role of volunteer interpreters from two different healthcare institutions in southern Spain. Based upon Bourdieu's Theory of Practice and the impact of structures and ethics, the author presents a detailed study of a group of volunteer interpreters as actors of the field of public service interpreting and the sub-field of healthcare interpreting. Drawing on observation, audio-recorded material and interviews as data, this thesis is a pioneering study in the field of public service interpreting and translation from an ethnographic point of view.

\section{Author: Mireia Vargas Urpi}

Title: Public Service Interpreting and Intercultural Mediation among the Chinese Community in Catalonia

Year: 2012

Place: Autonomus University of Barcelona (Spain)

Original language: Catalan

This academic research constitutes a valuable study of the Chinese community in different sectors in Catalonia. After a highly detailed theoretical framework, where the author describes the origins of PSIT in general, she focused her attention in Catalonia and the development of PSIT in this area. The role of the interpreter is studied from an institutional and socioprofessional perspective. There is a detailed analysis of the specificities of PSIT and the Chinese community, which yield relevant and interesting conclusions about this field of study. 